\title{
Short term effects of cigarette smoking on hospitalisation and associated lost workdays in a young healthy population
}

\author{
Anthony S Robbins, Vincent P Fonseca, Susan Y Chao, Gary A Coil, Nicole S Bell, \\ Paul J Amoroso
}

Office for Prevention and Health Services Assessment, Air Force Medical Operations Agency, Brooks Air Force Base, Texas, USA

A S Robbins

V P Fonseca

$S$ Y Chao

G A Coil

SDSS, Inc, Natick, Massachusetts, and Department of Social and Behavioral Sciences, Boston University School of Public Health, Boston, Massachusetts, USA

N S Bell

US Army Research Institute of

Environmental

Medicine, Natick,

Massachusetts, USA

P J Amoroso

Correspondence to: Major Anthony S Robbins, Office for Prevention and Health Services Assessment, 2602 Doolittle Road, Building 804, Brooks Air Force Base, Texas 78235-5249, USA anthony.robbins@ ophsa.brooks.af.mil

Received 18 November 1999 and in revised form

24 February 2000 . Accepted

10 March 2000

\begin{abstract}
Objective-There are relatively few published studies conducted among people of younger ages examining short term outcomes of cigarette smoking, and only a small number with outcomes important to employers. The present study was designed to assess the short term effects of smoking on hospitalisation and lost workdays.
\end{abstract}

Design-Retrospective cohort study.

Setting-Military population.

Subjects-87 991 men and women serving on active duty in the US Army during 1987 to 1998 who took a health risk appraisal two or more times and were followed for an average of 2.4 years.

Main outcome measures-Rate ratios for hospitalisations and lost workdays, and fraction of hospitalisations and lost workdays attributable to current smoking (population attributable fraction).

Results-Compared with never smokers, men and women who were current smokers had higher short term rates of hospitalisation and lost workdays for a broad range of conditions. Population attributable fractions (PAFs) for outcomes not related to injury or pregnancy were $7.5 \%$ (men) and $5.0 \%$ (women) for hospitalisation, and $14.1 \%$ (men) and $3.0 \%$ (women) for lost workdays. Evidence suggests that current smoking may have been under reported in this cohort, in which case the true PAFs would be higher than those reported.

Conclusions-In this young healthy population, substantial fractions of hospitalisations and lost workdays were attributable to current smoking, particularly among men.

(Tobacco Control 2000;9:389-396)

Keywords: young men; hospitalisation; lost workdays; employers

Cigarette smoking is a well established risk factor for a wide range of adverse health outcomes, including obstructive airway disease, cardiovascular disease, and cancer, ${ }^{1-3}$ and is the greatest single cause of premature mortality and preventable morbidity in the USA. ${ }^{4}$ The economic impact of smoking has been estimated at $\$ 50$ billion in direct medical costs and $\$ 47.2$ billion in indirect costs (in 1993 dollars). ${ }^{5}$ However, these estimates are based on models that are largely driven by outcomes associated with long latent periods, prolonged duration of exposure, or persons older than 35 years. The vast majority of studies on smoking and health have been conducted among middle aged or older persons; since the age at initiation for nearly all smokers is in early adolescence, older smokers will have smoked for long periods of time. ${ }^{7}$ The available studies on the health effects of smoking in younger persons are heavily concentrated on respiratory outcomes in children and adolescents, ${ }^{8-17}$ with other studies focusing on adverse effects on physical fitness ${ }^{18}{ }^{19}$ and pregnancy outcomes, ${ }^{20}{ }^{21}$ as well as the role of smoking in the early stages of atherosclerotic heart disease. ${ }^{22} 23$ There are fewer studies on smoking and health which have examined outcomes of particular importance to employers, many of whom provide health insurance for predominantly young workers. As a consequence, many employers may be unsure of the impact of smoking among their employees and may not appreciate the true value of a workplace culture that attracts a higher proportion of smoke free workers.

Lost workdays and outcomes with high cost, such as hospitalisations, have special significance for employers, because these outcomes result in significant work loss, potential economic losses, and human suffering. The modest number of studies examining smoking and these outcomes ${ }^{24-39}$ have generally relied on small samples and failed to adjust for important potential confounders. For example, one study included data from 7796 subjects, and did not adjust for alcohol use, obesity, and physical activity per se, but rather for the total number of risk factors (which included alcohol, obesity, and activity level, but also other factors) identified through a health risk appraisal. ${ }^{22}$ Although it is well established that these factors have independent and differing effects on health outcomes, the investigators assumed that all risk factors other than smoking had the same effect and combined all of their effects together. In spite of the study limitations, the investigators were able to demonstrate that current smokers were more likely to have higher future medical claims costs than non-smokers.

Prior studies have also generally not included sufficient numbers of younger persons to permit separate inferences for subjects under the age of 35 years, or have not presented age specific results. One study used 
data from 5780 subjects with a mean age of 51.9 years, and did not perform any adjustment for alcohol use, obesity, and physical activity when estimating the effect of smoking on future use of medical resources. ${ }^{24}$ Current and former smokers were found to have higher average monthly charges than never smokers, but current smoking was actually associated with a lower rate of hospitalisation. Another smaller study based on data from 1284 men and women presented separate results by age for men only, and found that current smoking was significantly related to future absenteeism costs (but not future medical claims costs) among younger and older men. ${ }^{26}$ Among women, current smoking was not significantly related to either type of future costs.

The present study was designed to assess the short term relationship between baseline self reported smoking status and rates of subsequent hospitalisation and associated lost workdays, using data from a large cohort of young healthy workers serving on active duty in the US Army.

\section{Methods}

STUDY POPULATION

The present study used data from the Total Army Injury and Health Outcomes Database (TAIHOD), obtained from the US Army Research Institute of Environmental Medicine, Natick, Massachusetts. ${ }^{40}$ TAIHOD is a longitudinal relational database which includes data on active duty US Army personnel, gathered from multiple military data sources. We used data on demographic characteristics, outcomes (hospitalisations and lost workdays), and health habits. The demographic data contained in the TAIHOD were obtained from the Defense Manpower Data Center, Monterey, California, the outcome data from the Individual Patient Data System database, and the health habit data from a file containing person level health risk appraisal (HRA) data. Personal identifiers-for example, encrypted social security numbers - were used to create initial data linkages and then removed from the working dataset in order to protect the privacy of the individual respondents to the HRA.

To be included in the study cohort, a subject must have completed two or more HRAs during the period 1987 to 1998 . For subjects who completed more than two HRAs during this period, we considered only the first and last. We used data from repeat HRA takers to prevent loss to follow up after entry into the study cohort, and to enable computation of the number of person years of observation for each subject (see statistical analysis below). The HRA is not taken by all US Army personnel. However, the primary reasons for its administration are for health habit screening during inprocessing to new assignments, as part of routine periodic physical examinations, or in conjunction with semi-annual physical fitness testing. HRA administration is directed by US Army policy and rarely initiated by individual soldiers. Thus, significant self selection bias is unlikely. To confirm that subjects in the study cohort were generally representative of the entire population of active duty US Army members, we compared demographic data for a subgroup of the study cohort (those completing their first HRA in 1992) with 1992 data for the entire active duty US Army population. We performed these comparisons using data from 1992, since this was the year with the largest number of persons entering the cohort: nearly $30 \%$ of the study subjects entered the cohort in this year. We did not observe any material differences in the distributions of age, sex, race, or military rank between the HRA respondents and the entire US Army population.

We excluded data on hospitalisations which were coded as having zero bed days or were missing data on the number of convalescent days associated with the hospitalisation (approximately 5\% of all hospitalisations). The proportion of subjects who had some hospitalisation data excluded was the same for current smokers, former smokers, and never smokers (approximately $1 \%$ for each of the three groups), suggesting that this exclusion did not bias our study findings.

Thus, the final study cohort included 87991 men and women serving on active duty in the US Army who completed two or more HRAs between 1987 and 1998. The study design resulted in an average follow up time of 2.4 years.

\section{STATISTICAL ANALYSIS}

If $\mathrm{Y}$ is the person-time rate observed for a stratum in a multiway contingency table, and $\mathrm{T}$ is the corresponding observed person-time, it is conventionally assumed that the number of cases observed for the stratum, A = YT, would tend to vary according to a Poisson distribution if the person-time were fixed at its observed value. For this reason, regression analysis of person-time rates is usually called Poisson regression. We used Poisson regression techniques to model the relationship between smoking status and rates of hospitalisation and lost workdays, while controlling for multiple covariates. Regressions were performed using the generalised linear modelling (GENMOD) procedure $^{41}$ in the SAS System for Microsoft Windows. ${ }^{42}$ Follow up was computed as the time between completion of the two HRAs. Smoking status was coded as current smoker, former smoker, or never smoker. (In the HRA, subjects were asked to choose one of these responses to describe their smoking status.) The following covariates were used in the statistical models: age $(<25$ years, 25-31 years, $>31$ years); sex; race (white, black, other); military rank (junior enlisted, E1-E4; senior enlisted, E5-E9; warrant officer, W1-W4; commissioned officer, O1-O10); number of alcoholic drinks consumed per week (none, 1-2, 3-5, > 5); frequency of aerobic exercise (rarely/never, $1-2$ times per week, $\geqslant 3$ times per week), and body mass index (weight $(\mathrm{kg})$ divided by height squared $\left(\mathrm{m}^{2}\right)$ ) (above or below $27.8 \mathrm{~kg} / \mathrm{m}$ for men, above or below $27.3 \mathrm{~kg} / \mathrm{m}$ for women). The cutpoints for the age categories represented tertiles of years of 
Table 1 Characteristics* of study subjects, active duty US Army personnel, 1987 to 1998

\begin{tabular}{|c|c|c|c|c|}
\hline \multirow[b]{2}{*}{ Characteristic } & \multicolumn{3}{|l|}{ Smoking status } & \multirow[b]{2}{*}{$P$ Valuet } \\
\hline & $\begin{array}{l}\text { Never smoker } \\
(57.9 \%)\end{array}$ & $\begin{array}{l}\text { Former smoker } \\
(15.6 \%)\end{array}$ & $\begin{array}{l}\text { Current smoker } \\
(26.5 \%)\end{array}$ & \\
\hline Follow up duration, years (mean) (SE) & $2.4(0.01)$ & $2.3(0.01)$ & $2.3(0.01)$ & $<0.0001$ \\
\hline Age, years (mean) (SE) & $27.7(0.03)$ & $31.2(0.07)$ & $28.6(0.05)$ & $<0.0001$ \\
\hline $\begin{array}{l}\text { Sex } \\
\quad \text { Male (\%) (SE) } \\
\text { Female (\%) (SE) }\end{array}$ & $\begin{array}{l}84.7(0.16) \\
15.3(0.16)\end{array}$ & $\begin{array}{l}89.1(0.27) \\
10.9(0.27)\end{array}$ & $\begin{array}{l}89.3(0.20) \\
10.7(0.20)\end{array}$ & $<0.001$ \\
\hline $\begin{array}{l}\text { Race } \\
\text { White (\%) (SE) } \\
\text { Black (\%)(SE) } \\
\text { Other (\%) (SE) }\end{array}$ & $\begin{array}{r}59.5(0.22) \\
34.2(0.21) \\
6.2(0.11)\end{array}$ & $\begin{array}{r}71.3(0.39) \\
21.9(0.35) \\
6.8(0.22)\end{array}$ & $\begin{array}{r}70.2(0.30) \\
23.6(0.28) \\
6.2(0.16)\end{array}$ & $<0.001$ \\
\hline $\begin{array}{l}\text { Military rank } \ddagger \\
\text { Junior enlisted (\%) (SE) } \\
\text { Senior enlisted (\%) (SE) } \\
\text { Warrant officer (\%) (SE) } \\
\text { Commissioned officer (\%) (SE) }\end{array}$ & $\begin{array}{r}40.5(0.22) \\
35.4(0.21) \\
2.6(0.07) \\
21.5(0.18)\end{array}$ & $\begin{array}{r}28.6(0.39) \\
51.4(0.43) \\
4.4(0.18) \\
15.6(0.31)\end{array}$ & $\begin{array}{r}43.5(0.33) \\
51.0(0.33) \\
2.0(0.09) \\
3.5(0.12)\end{array}$ & $<0.001$ \\
\hline Drinks of alcohol consumed per week (mean) (SE) & $2.4(0.02)$ & $3.6(0.05)$ & $5.2(0.06)$ & $<0.001$ \\
\hline $\begin{array}{l}\text { Frequency of aerobic exercise } \\
\text { Rarely/never }(\%)(\mathrm{SE}) \\
1-2 \text { times per week }(\%)(\mathrm{SE}) \\
\geqslant 3 \text { times per week }(\%)(\mathrm{SE})\end{array}$ & $\begin{array}{r}7.0(0.11) \\
27.4(0.04) \\
65.6(0.21)\end{array}$ & $\begin{array}{r}6.0(0.20) \\
25.7(0.37) \\
68.3(0.40)\end{array}$ & $\begin{array}{r}9.8(0.20) \\
31.2(0.31) \\
59.0(0.32)\end{array}$ & $<0.001$ \\
\hline Overweight, men (\%) (SE) S & $11.7(0.16)$ & $13.0(0.31)$ & $9.4(0.20)$ & $<0.001$ \\
\hline Overweight, women (\%) (SE)\ & $4.8(0.15)$ & $7.2(0.68)$ & $5.6(0.47)$ & $<0.001$ \\
\hline
\end{tabular}

SE, standard error.

^For demographic characteristics and risk factors, values shown are as of the beginning of follow up.

†For test of association between smoking status and the characteristic.

¥Military ranks were grouped as follows: junior enlisted (E1-E4); senior enlisted (E5-E9); warrant officer (W1-W4); and commissioned officer (O1-O10).

$\oint$ For men, body mass index $(\mathrm{BMI}) \geqslant 27.8 \mathrm{~kg} / \mathrm{m}^{2}$; for women, $\mathrm{BMI} \geqslant 27.3 \mathrm{~kg} / \mathrm{m}^{2}$.

age. For alcohol consumption categories, the cutpoints for non-zero values represented tertiles of weekly alcohol consumption among drinkers. For each of these covariates, the values used in the statistical models were those from the first HRA - that is, the values as of the beginning of follow up.

Hospitalisations were grouped into broad categories based on principal diagnosis, as coded using the International classification of diseases, ninth revision, clinical modification (ICD-9-CM). ${ }^{43}$ Data were used for all hospitalisations occurring during follow upthat is, between the two HRAs. Lost workdays associated with each hospitalisation were defined as the sum of bed days and convalescent days occurring before discharge from the hospital. Until very recently, military hospitals have allowed physicians to place patients on convalescent leave, a status in which they are allowed to leave the hospital but are still maintained on the hospital rolls. Patients then return to the hospital for reevaluation or testing and are finally discharged when they are deemed ready to return to duty. Convalescent days thus represent lost workdays in addition to actual bed days, but may represent only a portion of the total recovery time that an individual may require.

Since pregnancy related hospitalisations (ICD-9-CM codes 630-677 and V22-V28) represented $46 \%$ of all hospitalisations for women, and to allow creation of equivalent diagnostic groups for men and women, we analysed the data separately for this diagnostic category. Similarly, since some of the hospitalisations related to injury may be may uniquely related to military occupations, and since previous studies have shown that smoking may be an important risk factor for musculoskeletal injury in a wide range of activities and occupations, ${ }^{44-46}$ we also analysed data separately for injury related hospitalisations (ICD-9-CM codes 800-999). We excluded diagnoses related to poisoning (ICD-9-CM codes 909.0, 909.1, 909.5, and 960-989) from this diagnostic category. While the "injury" category used here encompasses more than musculoskeletal injuries, we felt that poisonings were sufficiently different in terms of their mechanism that they should be considered separately.

We computed rate ratios (RRs) and associated two sided $95 \%$ confidence intervals (CIs), separately comparing each of the two categories of smokers (current smokers and former smokers) to never smokers, while simultaneously adjusting for the covariates above. The following arguments can be offered in support of a causal relationship between smoking and the study outcomes: (1) biological plausibility, based on the causal role of smoking in a wide range of disease conditions; (2) consistency of the findings in the scientific literature ${ }^{24-39} 44-46$; (3) finding of a dose-response relationship in many of the studies; and (4) finding that use of health services declines dramatically after smoking cessation (versus continued smoking). ${ }^{28}$ Based on the assumption of causality, population attributable fractions (PAFs) for each diagnostic category were computed as $\mathrm{A} /(\mathrm{A}+1)$, where $\mathrm{A}=$ prevalence of current smoking among men or women $\times(R R-1)$. We performed all analyses separately for men and women, and for each of the two study end points (hospitalisations and lost workdays). 
Table 3 Short term effects of smoking on lost work day* rates among active duty US Army personnel, 1987 to 1998

\begin{tabular}{|c|c|c|}
\hline \multirow[b]{2}{*}{ Smoking status } & \multicolumn{2}{|l|}{ Rate ratio ${ }^{*}(95 \%$ CI $)$} \\
\hline & $\begin{array}{l}\text { Men (27.3\% current } \\
\text { smokers) }\end{array}$ & $\begin{array}{l}\text { Women (21.1\% current } \\
\text { smokers) }\end{array}$ \\
\hline \multicolumn{3}{|c|}{ Lost work days not related to injury or pregnancy (83719 lost work days) } \\
\hline Current smoker & $1.60(1.57$ to 1.63$)$ & $1.15(1.10$ to 1.19$)$ \\
\hline Former smoker & $1.21(1.19$ to 1.24$)$ & $0.94(0.90$ to 0.99$)$ \\
\hline Never smoker (referent category) & 1.00 & 1.00 \\
\hline \multicolumn{3}{|l|}{ Population attributable fraction } \\
\hline \multicolumn{3}{|c|}{ Injury related lost work days (12143 lost work days) } \\
\hline Current smoker & 1.07 (1.02 to 1.12$)$ & $1.54(1.31$ to 1.81$)$ \\
\hline Former smoker & $0.88(0.83$ to 0.94$)$ & $1.45(1.19$ to 1.77$)$ \\
\hline Never smoker (referent category) & 1.00 & 1.00 \\
\hline \multicolumn{3}{|l|}{ Population attributable fraction } \\
\hline (PAF) for current smoking (\%) & 1.8 & 10.2 \\
\hline \multicolumn{3}{|c|}{ Pregnancy related lost work days (24434 lost work days) } \\
\hline Current smoker & & $1.08(1.04$ to 1.12$)$ \\
\hline Former smoker & & $1.16(1.11$ to 1.21$)$ \\
\hline Never smoker (referent category) & & 1.00 \\
\hline \multicolumn{3}{|l|}{ Population attributable fraction } \\
\hline (PAF) for current smoking (\%) & & 1.6 \\
\hline
\end{tabular}

^Lost work days because of hospitalisation or associated convalescent days.

†Rate ratios are adjusted for age, race, military rank, alcohol consumption, exercise frequency, and overweight.

\section{Results}

BASELINE CHARACTERISTICS OF STUDY SUBJECTS Mean age at baseline for the study cohort was 28.5 years, and the average duration of follow up was 2.4 years. We found substantial differences in baseline characteristics across the three smoking status groups (current smoker, former smoker, never smoker) (table 1). Current smokers were slightly older than never smokers, and had a higher proportion of men and whites. Current smokers also had a higher proportion of senior enlisted personnel and a much lower proportion of commissioned officers. Average alcohol consumption was higher and frequency of aerobic exercise somewhat lower for current smokers, but there were no consistent differences in prevalence of overweight across the smoking status groups.

Table 2 Short term effects of smoking on hospitalisation rates among active duty US Army personnel, 1987 to 1998

\begin{tabular}{|c|c|c|}
\hline \multirow[b]{2}{*}{ Smoking status } & \multicolumn{2}{|l|}{ Rate ratio ${ }^{\star}(95 \% \mathrm{CI})$} \\
\hline & $\begin{array}{l}\text { Men }(27.3 \% \text { current } \\
\text { smokers) }\end{array}$ & $\begin{array}{l}\text { Women }(21.1 \% \text { current } \\
\text { smokers) }\end{array}$ \\
\hline \multicolumn{3}{|c|}{ Hospitalisations not related to injury or pregnancy (14710 hospitalisations) } \\
\hline Current smoker & $1.30(1.24$ to 1.35$)$ & $1.25(1.14$ to 1.37$)$ \\
\hline Former smoker & $1.20(1.14$ to 1.26$)$ & $1.13(1.01$ to 1.26$)$ \\
\hline Never smoker (referent category) & 1.00 & 1.00 \\
\hline \multicolumn{3}{|l|}{ Population attributable fraction } \\
\hline (PAF) for current smoking (\%) & 7.5 & 5.0 \\
\hline \multicolumn{3}{|c|}{ Injury related hospitalisations (1795 hospitalisations) } \\
\hline Current smoker & $1.03(0.91$ to 1.16$)$ & $1.11(0.73$ to 1.69$)$ \\
\hline Former smoker & $0.94(0.81$ to 1.09$)$ & $1.15(0.71$ to 1.85$)$ \\
\hline Never smoker (referent category) & 1.00 & 1.00 \\
\hline \multicolumn{3}{|l|}{ Population attributable fraction } \\
\hline (PAF) for current smoking (\%) & 0.7 & 2.3 \\
\hline \multicolumn{3}{|c|}{ Pregnancy related hospitalisations (2708 hospitalisations) } \\
\hline Current smoker & & $1.02(0.92$ to 1.14$)$ \\
\hline Former smoker & & $1.17(1.04$ to 1.32$)$ \\
\hline Never smoker (referent category) & & 1.00 \\
\hline \multicolumn{3}{|l|}{ Population attributable fraction } \\
\hline (PAF) for current smoking (\%) & & 0.4 \\
\hline
\end{tabular}

^ Rate ratios are adjusted for age, race, military rank, alcohol consumption, exercise frequency, and overweight.
SMOKING AND HOSPITALISATION

The short term effect of smoking on risk of hospitalisation differed for men and women, and also differed across diagnostic categories (table 2). The broadest diagnostic categoryhospitalisations not related to injury or pregnancy-captured $88 \%$ of all hospitalisations for men and $52 \%$ of all hospitalisations for women. Among men, current smoking was associated with a $30 \%$ increase in risk of being hospitalised for causes other than injury, and among women, current smokers had a $25 \%$ increased risk of hospitalisation for conditions not related to injury or pregnancy. We also observed smaller increases in risk of hospitalisation among former smokers (20\% increase among men and $13 \%$ among women). Assuming a causal relationship between smoking and hospitalisation not related to injury or pregnancy, $7.5 \%$ of these hospitalisations in men and $5.0 \%$ of these hospitalisations in women were attributable to current smoking.

We did not observe significant increases in risk of injury related or pregnancy related hospitalisation, although we had limited statistical power to detect a relationship between smoking and these outcomes, particularly among women. Hospitalisations related to injury represented $12 \%$ of all admissions for men and only $3 \%$ for women (absolute number of injury related admissions for women, 159).

Within the category of hospitalisations not related to injury or pregnancy, we compared the rates of hospitalisation for specific ICD-9-CM diagnoses across the smoking categories. Two diagnoses relating to inpatient treatment for alcohol dependence, codes 303.90 and 303.91 showed the largest difference in risk between current smokers and never smokers, after adjustment for the covariates listed above (for code 303.90, RR 3.99, 95\% CI 3.01 to 5.28; for code 303.91, RR $3.92,95 \%$ CI 2.69 to 5.71 ). Other diagnoses with large increases in risk among current smokers were code 786.50 , unspecified chest pain (RR 1.75, 95\% CI 1.14 to 2.68 ) and code 722.10 , displacement of lumbar intervertebral disc without myelopathy (RR 1.59, 95\% CI 1.10 to 2.30 ).

SMOKING AND LOST WORKDAYS

Similar to our findings for hospitalisation, the short term effect of smoking on risk of lost workdays differed for men and women, and also differed across diagnostic categories (table 3). The broadest diagnostic categoryhospitalisations not related to injury or pregnancy-captured $86 \%$ of all lost workdays for men and $39 \%$ of all lost workdays for women. For this diagnostic category, we found that current smoking was associated with a $60 \%$ increase in risk of lost workdays among men and a $15 \%$ increase in risk among women. Assuming a causal relationship between smoking and risk of lost workdays not related to injury or pregnancy, $14.1 \%$ of these lost workdays in men and $3.0 \%$ of these lost workdays in women were attributable to current smoking.

In contrast to our findings for hospitalisation, we did observe an increase in risk of lost 
workdays related to injury, particularly among women. Lost workdays related to injury captured $14 \%$ of lost workdays among men and $2 \%$ of lost workdays among women. Male current smokers experienced a $7 \%$ increased risk of lost workdays and female current smokers experienced a $54 \%$ increase in risk. Assuming a causal relationship between smoking and lost workdays related to injury, $1.8 \%$ of lost workdays in men and $10.2 \%$ of lost workdays in women were attributable to current smoking.

Pregnancy related conditions are common causes of hospitalisation among active duty US Army women. Lost workdays related to pregnancy captured 59\% of all lost workdays among women. We observed a small increase in risk of lost workdays related to pregnancy among both current smokers ( $8 \%$ increased risk) and former smokers ( $16 \%$ increased risk). Assuming a causal relationship between smoking and lost workdays related to pregnancy, $1.6 \%$ of these lost workdays were attributable to current smoking.

RESULTS FOR COVARIATES

Tables 2 and 3 show results for associations between smoking and the study outcomes, adjusted for several covariates. However, some readers may also be interested in the relationships between these covariates and the outcomes, adjusted for smoking and the other covariates. Because of space limitations, only results for hospitalisation not related to pregnancy or injury are reported. Risk factor definitions are shown in table 1. Referent categories (RR 1.00) are as follows: for age, $<25$ years; for race, white; for military rank, commissioned officer; for alcohol consumption, none (non-drinkers); for aerobic exercise frequency, $\geqslant 3$ times per week.

\section{Results for men}

For each covariate, the RR and associated 95\% CI are as follows: age 25-31 years, $1.04(0.98$ to 1.10$)$; age $32-64$ years, 1.46 (1.37 to 1.56$)$; black race, 0.89 (0.86 to 0.93 ); other race, 0.91 (0.84 to 0.99$)$; junior enlisted rank, 1.24 (1.15 to 1.33 ); senior enlisted rank, 1.16 (1.10 to 1.23); warrant officer rank, 0.97 (0.86 to 1.09$)$; alcohol consumption of 1-2 drinks/week, 0.90 (0.86 to 0.95$)$; alcohol consumption of 3-5 drinks/week, 0.93 (0.89 to 0.98); alcohol consumption of $>5$ drinks/week, 0.90 (0.86 to 0.95); aerobic exercise frequency of rarely/ never, 1.29 (1.21 to 1.38); aerobic exercise frequency of 1-2 times/week, 1.10 (1.05 to 1.15); and overweight, 1.27 (1.21 to 1.35 ).

\section{Results for women}

For each covariate, the RR and associated 95\% CI are as follows: age 25-31 years, $1.03(0.93$ to 1.14 ); age $32-64$ years, 1.41 (1.26 to 1.58 ); black race, 0.92 (0.85 to 1.00$)$; other race, 0.93 (0.81 to 1.08$)$; junior enlisted rank, 1.47 (1.28 to 1.68$)$; senior enlisted rank, 1.27 (1.12 to 1.44); warrant officer rank, 1.17 (0.73 to 1.85$)$; alcohol consumption of 1-2 drinks/week, 1.03 (0.94 to 1.13); alcohol consumption of 3-5 drinks/week, 1.10 (0.98 to 1.23); alcohol consumption of $>5$ drinks/week, 0.96 (0.83 to 1.12); aerobic exercise frequency of rarely/ never, 1.27 ( 1.14 to 1.41 ); aerobic exercise frequency of 1-2 times/week, 1.00 (0.92 to 1.08); and overweight, 1.11 (0.95 to 1.31$)$.

\section{Discussion}

In this young healthy population of active duty US Army personnel, current cigarette smoking accounted for substantial fractions of hospitalisations and lost workdays, particularly among men. For hospitalisations not related to injury or pregnancy, PAFs for current smoking were $7.5 \%$ among men and $5.0 \%$ among women. For lost workdays not related to injury or pregnancy, the PAF for current smoking was substantially larger among men $(14.1 \%)$ and somewhat smaller among women $(3.0 \%)$. It is remarkable that a single risk factor could account for such a large proportion of hospitalisations and lost workdays, particularly over such a short period of observation. For example, these findings indicate that, all other factors being equal, if the entire active duty US Army population became never smokers, the number of lost duty days not related to injury among men might drop by as much as $18.3 \%$ in under 2.5 years. It is hard to imagine a change in another single risk factor that would have a larger short term impact on absenteeism rates.

Because we did not study a smoking cessation intervention, our results can only indicate the potential benefits from "substituting" never smokers in place of the current smokers in the active duty population. This situation only occurs when current smokers leave active duty and an equal number of never smokers are recruited to replace them. Given that a complete substitution of never smokers for all current smokers is unlikely, it is reasonable to ask what the study findings may imply regarding smoking cessation efforts-that is, the effect of changing current smokers to former smokers. Our observational data were not adequate to address this question, because the former smokers in our cohort may have decided to quit based on adverse changes in their health status. However, Wagner and colleagues $^{28}$ conducted a randomised control trial of smoking cessation and found that by the fourth year after quitting, demand for health care was significantly lower among quitters than among those who continued to smoke. Wagner and colleagues did not include data from never smokers, so it is not known whether demand for health care decreased to the level of never smokers. One may therefore hypothesise that effective smoking cessation efforts in the US Army population would require several years to produce the benefits suggested in the present study, and that the benefits might not be as large as those from "substituting" never smokers in place of current smokers.

Even among the modest number of studies examining the effects of smoking on health care utilization and/or worker absenteeism, there have been some inconsistencies in the findings. Thus, our results agree with those of 
some prior studies and disagree with others. Several studies have reported that current smokers have higher hospitalisation rates $^{28} 3035$ and bed day rates ${ }^{26} 2936$ than never smokers. Terry and colleagues ${ }^{21}$ found, however, that among subjects under age 65, current smokers actually had lower hospitalisation rates than never smokers. In an analysis of bed day rates, Marsden and colleagues ${ }^{31}$ did not find that current smokers had higher rates compared with never smokers. Yen and associates ${ }^{23}$ found that absenteeism costs were higher among male smokers but not among female smokers.

Our findings are very different from those of Helyer and colleagues, ${ }^{47}$ who estimated that only $1.5 \%$ of bed days among active duty US military personnel (all service branches combined) were attributable to current smoking. In this earlier study, only bed days were considered, whereas the present study also considers convalescent days associated with a hospitalisation. Moreover, Helyer and colleagues only included certain diagnoses in their analyses, whereas we included all diagnoses (considered within broad categories). The fact that the earlier study included only bed days is not likely to entirely account for the difference in findings, since in the present study nearly two of every three lost workdays were contributed by bed days. The difference in findings is likely caused by the restricted set of diagnoses considered in the earlier study, and to the fact that Helyer and colleagues $^{47}$ did not actually compare bed day rates in smokers and non-smokers, but rather estimated the effect of smoking using a model that was designed to make inferences to persons aged 35 years and older.

Because smoking status at entry into the study cohort is used as the exposure measure in the present study, our results estimate the effect of smoking at one point in time on future hospitalisation and lost workdays, with no restriction on whether subjects quit smoking later. The study inferences are primarily of interest to employers (and other payers of health related costs) at the time of hiring, since the study is designed to assess the expected future increase in risk of hospitalisations and lost workdays among current smokers compared with never smokers. Thus, we have designed the study from the employer perspective- that is, acknowledging that some persons who smoke at the time of hiring will later quit.

Whenever studies are conducted in active duty military populations, concern inevitably arises regarding the generalisability of the findings to civilian populations. However, this concern is rarely substantiated by data. Nonetheless, since fertility patterns, risk factors for adverse pregnancy outcomes, and injury patterns may differ between military and civilian populations, we have focused on our findings for hospitalisations not related to injury or pregnancy. Within this category, the specific ICD-9-CM diagnoses showing the largest adjusted differences in risk between current smokers and never smokers were related to alcohol dependence, chest pain, and lumbar intervertebral disc displacement. Asso- ciations between cigarette smoking and each of these conditions have been described in the civilian literature, suggesting that our main results are not unique to the military setting. In addition, far from being homogeneous with respect to demographic or occupational characteristics, the active duty US Army population is a diverse one with respect to ethnicity, race, and sex, and with occupational classifications ranging from cooks and bus drivers to engineers and attorneys. There are actually few occupational classifications which are unique to the US Army - that is, classifications having no civilian equivalent.

There are a few potential sources of bias in the present study that should be noted. First, the exposure data are self reported and unverified. Variables regarding health behaviours such as cigarette smoking and alcohol consumption may be particularly susceptible to under reporting because of the recent emphasis on health promotion throughout the Department of Defense. Additionally, we only measured lost workdays associated with hospitalisation, since we did not have data on lost workdays associated with illnesses not requiring hospitalisation. It is likely that the number of lost workdays not associated with hospitalisation would be far larger than the number observed in the present study. Currently, outpatient visits in the Army Medical Service are approximately 170 times more frequent than hospitalisations on an annual basis. ${ }^{48}$ If a similar association existed between smoking and ambulatory visits and associated lost work time, then the true effect of smoking would be substantially greater than the findings of the present study suggest.

There is evidence suggesting that current smoking was under reported in this cohort. While we estimated the prevalence of current smoking was $27.3 \%$ among men and $21.1 \%$ among women, estimates of current smoking prevalence from the 1992 worldwide survey of substance abuse and health behaviours among military personnel (hereafter referred to as WWS) were $38.2 \%$ and $29.8 \%$ among active duty US Army men and women, respectively. ${ }^{49}$ The WWS is conducted by a civilian research organisation under contract to the Department of Defense. Unlike the HRA, the WWS uses anonymous interviews in an effort to maximise response to sensitive questions, including items on illicit drug use. The definition of current smoking is slightly more restrictive in the WWS, since it requires not only smoking in the last 30 days, but also a lifetime total of at least 100 cigarettes smoked. Approximately $74 \%$ of the subjects in the present study entered the cohort during 1991 to 1993, with the largest number entering in 1992. The remaining 23\% entered during 1994 to 1996. Analogous results from the 1995 WWS were $35.1 \%$ and $27.5 \%$ for men and women, respectively. ${ }^{50}$ Using a weighted average of the 1992 and 1995 WWS results leads to current smoking prevalence estimates of $37.5 \%$ for men and $29.2 \%$ for women - again, substantially higher than we observed. If study subjects did underreport current smoking, this would cause us to 
underestimate the PAFs in tables 2 and 3. Additionally, under reporting of current smoking would also affect RR estimates, biasing estimates for current smoking toward null findings. As noted above, other health related behaviours may also have been inaccurately reported because of social expectations regarding behaviour. The effect of such misclassification on the observed RR for current smoking would be to increase the RR in some cases, and to decrease it in others.

The data presented here suggest that current smoking accounts for substantial fractions of hospitalisations and lost workdays among young healthy employees, particularly among men. The fact that smoking had smaller effects among women is particularly interesting and begs further investigation. It is possible that ascertainment of smoking status is less accurate among women because of a tendency to quit during pregnancy and lactation. Exploration of these and other potential explanations of the sex differences seen in the present study were beyond the scope of this preliminary investigation. While further work is needed to describe the relationship between smoking and the risk of specific diagnoses within each of the broad categories used in the present study - particularly injuries and musculoskeletal conditions - these findings support current initiatives within the Department of Defense to decrease the prevalence of current smoking. Reductions in the prevalence of current smoking may result in substantial decreases in health related costs, lost productivity, and human suffering associated with hospitalisations and lost workdays.

We are grateful to Ms Michelle Yore for programming of the TAIHOD database and creation of the dataset used for the present study. Dr Bell is supported in part by grant R29 AA11407-01A1 from the National Institute on Alcoholism and Alcohol Abuse. The views and opinions expressed in this paper are those of the authors only, and do not represent the official position of the US Air Force or US Army, the Department of Defense, or the National Institute on Alcoholism and Alcohol Abuse.

1 US Department of Health and Human Services. The health consequences of smoking: chronic obstructive lung disease. A report of the Surgeon General, 1984. Rockville, Maryland: Public Health Service, Office on Smoking and Health 1984. (DHHS Publication No (PHS) 84-50205.)

2 US Department of Health and Human Services. The health consequences of smoking: cardiovascular disease. A report of the
Surgeon General, 1983. Rockville, Maryland: Public Health Service, Office on Smoking and Health, 1983. (DHHS Publication No (PHS) 84-50204.)

3 US Department of Health and Human Services. The health consequences of smoking: cancer. A report of the Surgeon Gen-
eral, 1982. Bethesda, Maryland: Public Health Service, eral, 1982. Bethesda, Maryland: Public Health Service, Office on Smoking and

4 Centers for Disease Control and Prevention. Cigarette smoking among adults-United States, 1992, and changes in the definition of current cigarette smoking. $M M W R$ Morbid Mortal Wkly Rep 1994;43:342-6.

5 Centers for Disease Control and Prevention. Medical care expenditures attributable to cigarette smoking - United States, 1993.MMWR Morbid Mortal Wkly Rep 1994; 43:469-72.

6 Centers for Disease Control. Cigarette smoking-attributable mortality and years of potential life lost - United States, 1990.MMWR Morbid Mortal Wkly Rep 1993;42:645-9.

7 US Department of Health and Human Services. Preventing tobacco use among young people. A report of the Surgeon General, 1994. Atlanta, Georgia: Public Health Service, Centers for Disease Control and Prevention, Office on Smoking and Health, 1994. (US Government Printing Office Publication No S/N 017-001-00491-0.)

8 Peters JM, Ferris BG. Smoking, pulmonary function and respiratory symptoms in a college-age group. Am Rev Respir Dis 1967;95:774-82.
9 Seeley JE, Zuskin E, Bouhuys A. Cigarette smoking: objective evidence for lung damage in teenagers. Science 1971;172:741-3.

10 Rush D. Respiratory symptoms in a group of American secondary school students: the overwhelming association with cigarette smoking. Int $\mathcal{F}$ Epidemiol 1974;3:153-65.

11 Bland M, Bewley BR, Pollard V, Banks MH. Effect of children's and parents' smoking on respiratory symptoms. Arch Dis Child 1978;53:100-5.

12 Charlton A. Children's coughs related to parental smoking. BMF 1984;288:1647-9.

13 Oechsli FW, Seltzer CC, van den Berg BJ. Adolescent smoking and early respiratory disease: a longitudinal study. Ann Allergy 1987;59:135-40.

14 Backhouse CI. Peak expiratory flow in youths with varying cigarette smoking habits. BMF 1975;i:360-2.

15 Spinaci S, Arossa W, Bugiani M, Natale P, Bucca C, de Candussio G. The effects of air pollution on the respiratory health of children: a cross-sectional study. Pediatr Pulmonol 1985;1:262-6.

16 Finklea JF, Hasselblad V, Sandifer SH, Hammer DI, Lowrimore GR. Cigarette smoking and acute non-influenzal respiratory disease in military cadets. Am $f$ Epidemiol 1971;93:457-62.

17 Kark JD, Lebiush M, Rannon L. Cigarette smoking as a risk factor for epidemic A(H1N1) influenza in young men. $N$ Engl f Med 1982;307:1042-6.

18 Royal College of Physicians of London. Smoking and the young. London: Lavenham Press, 1992.

19 Sidney S, Sternfeld B, Gidding SS, et al. Cigarette smoking and submaximal exercise test duration in a biracial population of young adults: the CARDIA study. Med Sci Sports Exerc 1993;25:911-6.

20 US Department of Health and Human Services. The health consequences of smoking for women. A report of the Surgeon General, 1980. Rockville, Maryland: Office of the Assistant Secretary for Health, Office on Smoking and Health, 1980. (DHHS Publication No (CDC) 90-8416.)

21 Health Services and Mental Health Administration. The Health Consequences of Smoking: A report of the Surgeon General, 1971. Rockville, MD: US Public Health Service, 1971. (DHEW publication no. (HSM) 71-7513.)

22 Strong JP, Richards ML. Cigarette smoking and atherosclerosis in autopsied men. Atherosclerosis 1976;23:451-76.

23 Berenson GS, Wattigney WA, Tracy RE, et al. Atherosclerosis of the aorta and coronary arteries and cardiovascular risk factors in persons aged 6 to 30 years and studied at necropsy (the Bogalusa heart study). Am $\mathcal{f}$ Cardiol 1992;70:851-8

24 Terry PE, Fowler EJ, Fowles JB. Are health risks related to medical care charges in the short-term? Challenging traditional assumptions. Am f Health Promot 1998;12:340-7.

25 Yen LT, Edington DW, Witting P. Corporate medical claim cost distributions and factors associated with high-cost status. F Occup Med 1994;36:505-15.

26 Yen LT, Edington DW, Witting P. Prediction of prospective medical claims and absenteeism costs for 1284 hourly workers from a manufacturing company. $f$ Occup Med 1992;34:428-35.

27 Yen LT, Edington DW, Witting P. Associations between health risk appraisal scores and employee medical claims costs in a manufacturing company. Am $\mathcal{F}$ Health Promot $1991 ; 6: 46-54$.

28 Wagner EH, Curry SJ, Grothaus L, Saunders KW, McBride $\mathrm{CM}$. The impact of smoking and quitting on health care use. Arch Intern Med 1995;155:1789-95.

29 Vogt TM, Schweitzer SO. Medical costs of smoking in a health maintenance organization. Am f Epidemiol 1985; 122:1060-6.

30 Oakes TW, Friedman GD, Seltzer CC, Siegelaub AB, Collen MF. Health service utilization by smokers and nonsmokers. Med Care 1974;12:958-66.

31 Ashford JR. Smoking and the use of the health services. $\mathrm{Br} F$ Prev Soc Med 1973;27:8-17.

32 Newcomb MD, Bentler PM. The impact of late adolescent substance use on young adult health status and utilization of health services: a structural equation model over four years. Soc Sci Med 1987;24:71-82.

33 Kaplan RM, Wingard DL, McPhillips JB, Williams-Jones D, Barrett-Connor E. Cigarette smoking, mortality, institutional and community-based care utilization in an adult community. F Commun Health 1992;17:53-60.

34 Marsden ME, Bray RM, Herbold JR. Substance use and health among US military personnel: findings from the 1985 worldwide survey. Prev Med 1988;17:366-76.

35 Edington DW, Yen LT, Witting P. The financial impact of changes in personal health practices. $f$ Occup Med 1997;39:1037-46.

36 Edington DW, Yen L. Is is possible to simultaneously reduce risk factors and excess health care costs? Am F Health Promot 1992;6:403-9.

37 Leigh JP, Fries JF. Health habits, health care use and costs in a sample of retirees. Inquiry 1992;29:44-54.

38 Penner M, Penner S. Excess insured health care costs from tobacco-using employees in a large group plan. $f$ Осcиp Med 1990;32:521-3.

39 Happanen-Niemi N, Miilunpalo S, Vuori I, Pasanen M, Oja P. The impact of smoking, alcohol consumption, and physical activity on use of hospital services. Am f Public Health 1999;89:691-8.

40 Amoroso PJ, Yore MM, Weyandt B, Jones BH. A model comprehensive research database: total army injury and health outcomes database. Mil Med In press. 
41 SAS Institute. SAS/STAT software: the GENMOD procedure, release 6.09. SAS technical report P-243. Cary, North Carolina: SAS Institute, 1993 .

42 SAS Institute. SAS System under Microsoft Windows, release 6.12 (TS050). Cary, North Carolina: SAS Institute, 1996

43 Health Care Financing Administration. International classification of diseases, ninth revision, clinical modification: ICD-9 $C M$. 4th ed. Washington, DC: US Public Health Service, 1991. (DHHS publication no. (PHS) 91-1260.

44 Reynolds KL, Heckel HA, Witt CE, et al. Cigarette smoking, physical fitness, and injuries in infantry soldiers. Am f Prev Med 1994;10:145-50.

45 Sacks J, Nelson D. Smoking and injuries: an overview. Prev Med 1994;23:515-20.

46 Amoroso P, Reynolds K, Barnes J, White D. Tobacco and injury: an annotated bibliography. Technical note prepared for the US Army Research Institute of Environmared Medicine, March 1996. USARIEM publicationental TN96- 1 .
47 Helyer AJ, Brehm WT, Perino L. Economic consequences of tobacco use for the Department of Defense, 1995. Mil Med 1998:163:217-21.

48 US Army Center for Health Promotion and Preventive Medicine. Medical Surveillance Monthly Report 1999; 5(3): $1-31$

49 Bray RM, Kroutil LA, Luckey JW, et al. 1992 worldwide survey of substance abuse and health behaviors among military personnel. Research Triangle Park, North Carolina: Research Triangle Institute, 1992.

50 Bray RM, Kroutil LA, Wheeless SC, et al. 1995 Department of Defense survey of health related behaviors among military personnel. Research Triangle Park, North Carolina: Research Triangle Institute, 1995.

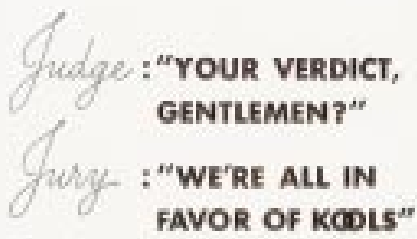

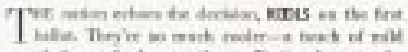

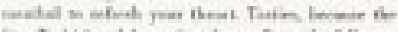

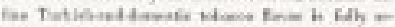

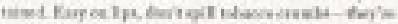

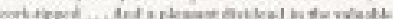

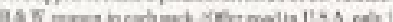
Ne

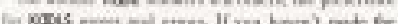

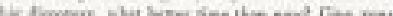
trizesches

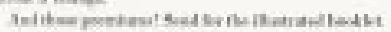

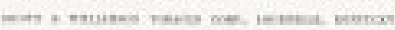
MILECY MENTHOLATE ... CORK TIFHED

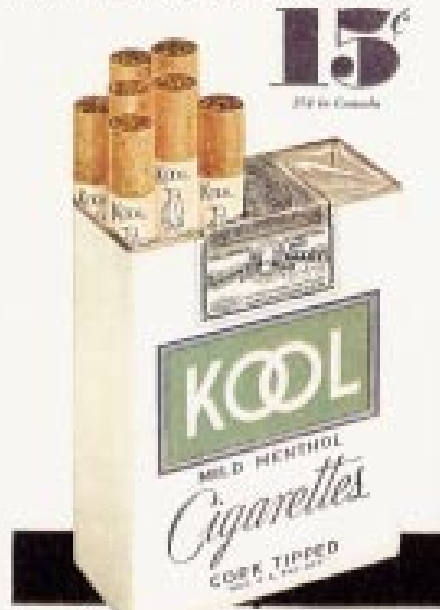

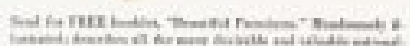

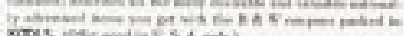
pores peer nedise sis a mit

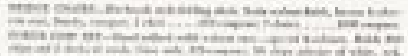

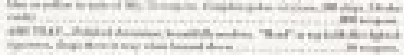

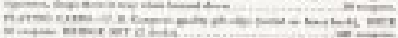
cicmer mats

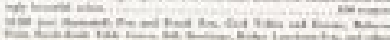
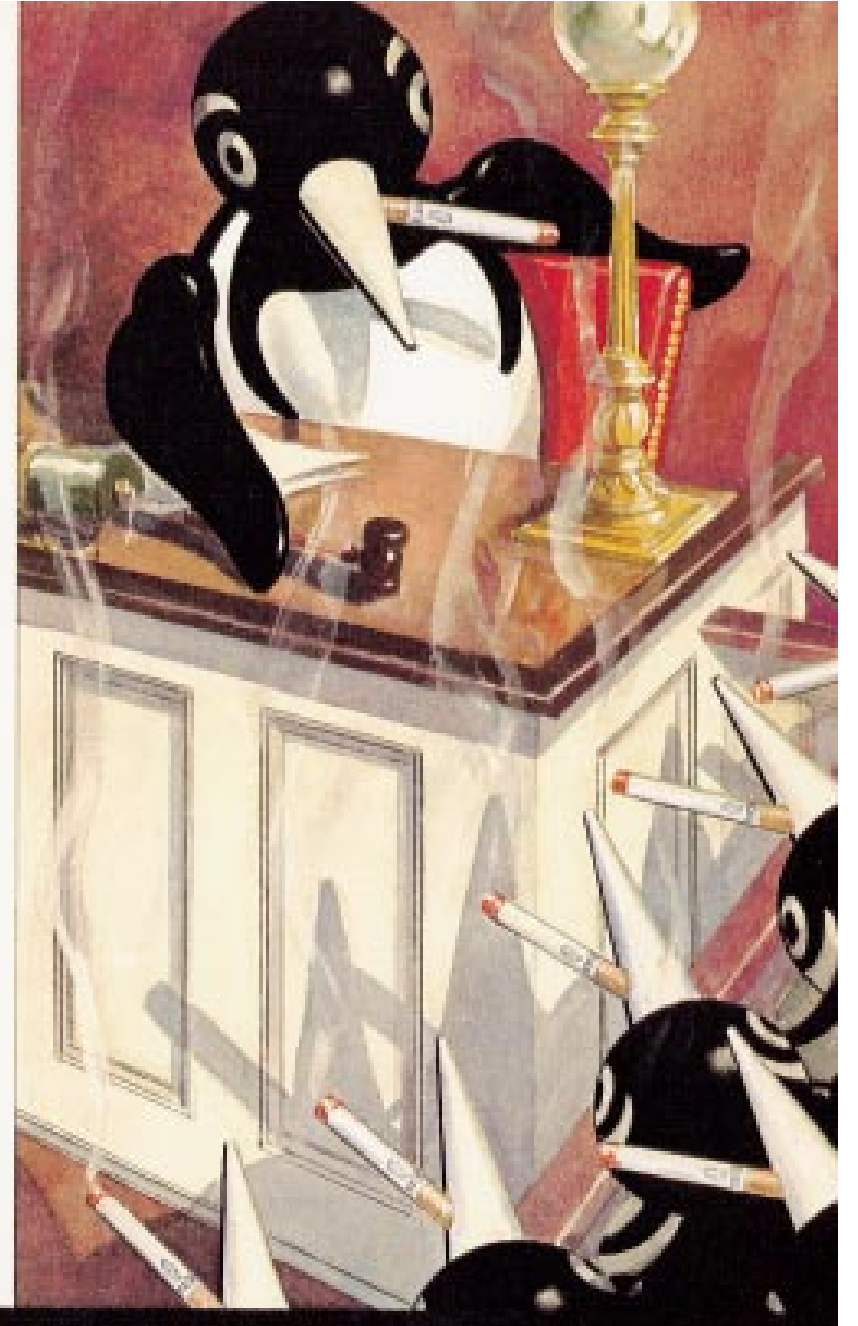

SAVE B \& W COUPONS FOR HANDSOME NOW PREMIUMS

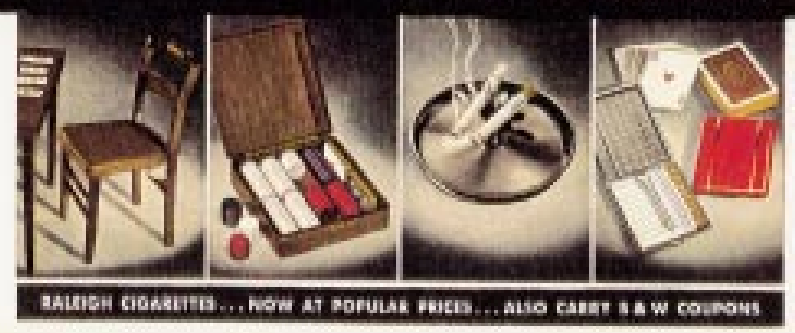

Contributed by Melanie Wakefield. 